\title{
Chronic Sulfonylurea Treatment and Hyperglycemia Aggravate Disproportionately Elevated Plasma Proinsulin Levels in Patients with Type 2 Diabetes
}

\author{
ToYoshi INOGUCHI, Fumio UMEDA, MAIKo KAKIMOTO, YASUHIRo SAKO, HideHIRo ISHII, \\ Katsumi NODA, MaKoto KUNISAKI, MinaKo IMAMURA, HaI-Yan YU, TaKashi ETOH, \\ HiRoyasu YOSHIKAWA, TsuYoshi AOKI, Toshiniko HASHIMOTO aNd HaJIME NAWATA
}

Department of Medicine and Bioregulatory Science, Graduate School of Medical Sciences, Kyushu University, Fukuoka 812-8582, Japan

\begin{abstract}
It is established that disproportionately elevated plasma proinsulin levels occur in patients with Type 2 diabetes. In the present study, multivariate analysis was performed to determine what factors contributed to the disproportionately elevated plasma proinsulin levels in Japanese patients with Type 2 diabetes $(n=276)$. Results from univariate analysis showed that both fasting proinsulin/C-peptide ratio and proinsulin/IRI ratio were approximately 2 -fold higher in patients with Type 2 diabetes than those in healthy nondiabetic subjects $(n=45)$. In patients with Type 2 diabetes, both proinsulin/C-peptide ratio and proinsulin/IRI ratio were significantly positively correlated with fasting plasma glucose level (FPG) and $\mathrm{HbA}_{1 \mathrm{c}}$. Neither proinsulin/C-peptide ratio nor proinsulin/IRI ratio was significantly correlated with BMI. Sulfonylurea-treated subjects had a significant elevation in both proinsulin/C-peptide ratio and proinsulin/IRI ratio compared with diet-treated subjects, whereas nonsulfonylurea hypoglycemic agent-treated subjects did not. Multivariate analysis confirmed that sulfonylurea treatment and FPG were significant determinants of both fasting proinsulin/C-peptide ratio $(P=0.006$ and $P=0.030$, respectively) and proinsulin/IRI ratio $(P=0.003$ and $P=0.016$, respectively) in patients with Type 2 diabetes. These results imply that disproportionate hyperproinsulinemia may reflect an excessive overwork of $\beta$ cells under chronic sulfonylurea treatment as well as hyperglycemia.
\end{abstract}

Key words: Proinsulin, Type 2 diabetes, Hyperglycemia, Sulfonylurea

(Endocrine Journal 47: 763-770, 2000)

IT is well established that plasma proinsulin levels are disproportionately elevated relative to plasma insulin levels in patients with Type 2 diabetes [1-6]. However, the cause of this disproportionate hyperproinsulinemia remains unclear. Epidemiological studies have shown that fasting proinsulin to insulin (proinsulin/insulin) ratio is positively correlated with the degree of hyperglycemia in patients with Type 2

Received: March 31, 2000

Accepted: October 4, 2000

Correspondence to: Toyoshi INOGUCHI, M.D., Department of Medicine and Bioregulatory Science, Graduate School of Medical Sciences, Kyushu University, Maidashi 3-1-1, Higashi-ku, Fukuoka 812-8582, Japan diabetes [3, 7-9]. One possible explanation for this phenomenon is that sustained secretory demand on the $\beta$ cells in response to hyperglycemia may deplete mature granules so that immature proinsulin-rich granules end up being released. Alternatively, chronic hyperglycemia could impair proinsulin processing. One report showed that $90 \%$ pancreatectomized rats with hyperglycemia induced a fall in insulin content and a raised proportion of proinsulin in pancreas extracts [10]. In hemipancreatectomy in humans, a disproportionate elevation in fasting proinsulin levels was also reported [11]. Taken together, these findings support the notion that disproportionate hyperproinsulinemia may be due to excessive secretory demand on $\beta$ cells. We 
speculated that chronic $\beta$ cells stimulation by sulfonylurea as well as hyperglycemia might modulate the disproportionate hyperproinsulinemia in patients with Type 2 diabetes, provided that the increased secretory demand is critical for disproportionate hyperproinsulinemia. However, the effect of treatment with sulfonylurea or other hypoglycemic agents on the disproportionate hyperproinsulinemia is still controversial [12-16]. Several studies have shown that short-term treatment with sulfonylurea (4 or 8 weeks) has no effect on the disproportionate hyperproinsulinemia [12-14] or even restored it in patients with Type 2 diabetes [15]. In the present study, fasting plasma proinsulin/C-peptide ratio and proinsulin/IRI ratio were measured in 276 Japanese patients with Type 2 diabetes and multivariate analysis was performed to determine what factors contributed to the disproportionate hyperproinsulinemia in these patients.

\section{Methods}

A total of 276 patients with Type 2 diabetes who visited Kyushu University Hospital, Kitakyushu Medical Center, Saiseikai Fukuoka General Hospital, and Hara Sanshin Kai Hospital from January 10 to January 24 in 1998 were consecutively recruited for the study, along with 42 nondiabetic control subjects of similar age and level of obesity. Nondiabetic control subjects all had normal fasting plasma glucose level and normal response to standard glucose tolerance test. Diabetic subjects were 61.0 \pm 0.6 years of age and had a mean BMI of $23.0 \pm$ 0.2 , and control subjects were $59.6 \pm 2.4$ years of age and had a mean BMI of $23.3 \pm 0.7$. Diabetic subjects had $9.8 \pm 0.5$ years of duration, and had been treated with diet only, sulfonylurea (glibenclamide, gliclazide), non-sulfonylurea hypoglycemic agents (metformin, alfa-glucosidase inhibitor, or troglitazone), combination of sulfonylurea and non-sulfonylurea agents, and insulin injection. Informed consent was obtained from all subjects.

Blood samples were taken for the measurement of fasting plasma glucose (FPG), $\mathrm{HbA}_{1 \mathrm{c}}$, immunoreactive insulin (IRI), C-peptide concentrations, and total proinsulin concentration after overnight fasting. FPG was determined by the glucose oxidase method. Plasma C-peptide concentrations were assayed by double-antibody solid-phase radioimmunoassay (Shionogi Kit, Shionogi Co., Osaka, Japan) that has cross-reactivity of $31 \%$ with human proinsulin. Intra- and interassay coefficients of variation of this assay were $6.0-8.0 \%$ and $5.0-8.1 \%$, respectively. Plasma IRI was determined by a double-antibody solid-phase radioimmunoassay (Dainabot Co., Tokyo, Japan) that has no cross-reactivity with human proinsulin or C-peptide at concentrations of less than $10 \mu \mathrm{g} / \mathrm{ml}$. Intra- and interassay coefficients of variation of this assay were $1.9 \%-3.3 \%$ and $1.2-$ $1.9 \%$, respectively. Plasma proinsulin was measured by a two-site sandwich enzyme-linked immunosorbent assay (Yuka Medias, Co., Tokyo, Japan) with biotinylated anti-human insulin monoclonal antibodies (HUI-018, DAKO A/S, Denmark) and anti-human $\mathrm{C}$-peptide monoclonal antibody (PEP-001, DAKO A/S, Denmark). The detailed characterization of this method was as previously described [17]. Both intact proinsulin and proinsulin conversion intermediates (split and des-proinsulin) were fully recognized in this proinsulin assay. In this paper, plasma proinsulin is used to refer to plasma intact proinsulin and proinsulin conversion intermediates combined. There was no detectable cross-reactivity of insulin or C-peptide in the proinsulin assay. Minimal detection limit was approximately $0.1 \mathrm{pmol} / \mathrm{l}$, and the intra- and interassay coefficients of variation were $3.1-3.7 \%$ and 5.0 $14.9 \%$, respectively.

\section{Statistical analysis}

Descriptive results of continuous variables were expressed as mean $\pm \mathrm{SE}$. As none of variables were normally distributed, we used the Mann-Whitney $U$ test for comparing groups and Spearman's test for determining correlation coefficients. When comparing diet-treated subjects to hypoglycemic agent-treated subjects, Dunnett's Post-hoc analysis was performed. We also performed multivariate analysis to evaluate what variables were determinants of fasting proinsulin/C-peptide ratio or fasting proinsulin/IRI ratio in patients with Type 2 diabetes.

\section{Results}

Table 1 shows fasting plasma proinsulin concen- 
Table 1. Fasting proinsulin, C-peptide, IRI, proinsulin/C-peptide ratio and proinsulin/IRI ratio in patients with Type 2 diabetes and nondiabetic control subjects.

\begin{tabular}{lccc}
\hline Variables & Control & $\begin{array}{c}\text { Type } 2 \\
\text { diabetes }\end{array}$ & P value \\
\hline Proinsulin (pmol/l) & $8.8 \pm 1.1$ & $16.3 \pm 0.9$ & $\mathrm{P}<0.0001$ \\
C-peptide (nmol/l) & $0.80 \pm 0.07$ & $0.70 \pm 0.02$ & $\mathrm{NS}$ \\
IRI (pmol/l) & $55.8 \pm 7.5$ & $52.6 \pm 4.9$ & $\mathrm{NS}$ \\
Proinsulin/C-peptide ratio $\left(\times 10^{-3}\right)$ & $10.4 \pm 0.7$ & $22.8 \pm 0.9$ & $\mathrm{P}<0.0001$ \\
Proinsulin/IRI ratio & $0.19 \pm 0.03$ & $0.41 \pm 0.01$ & $\mathrm{P}<0.0001$ \\
\hline
\end{tabular}

Data are mean \pm SE. Significance of variables was determined by Mann-Whitney U test.

tration, IRI, C-peptide concentration, proinsulin/Cpeptide ratio and proinsulin/IRI ratio in patients with Type 2 diabetes and nondiabetic control subjects. Plasma proinsulin concentrations were significantly higher in patients with Type 2 diabetes than control subjects $(16.28 \pm 0.89$ vs. $8.83 \pm 1.11 \mathrm{pmol} / \mathrm{l}$, $\mathrm{P}<0.0001$ ), whereas there was no significant difference in C-peptide and IRI concentrations. Both proinsulin/C-peptide ratio and proinsulin/IRI ratio were significantly higher in patients with Type 2 diabetes than control subjects $(10.40 \pm 0.73$ vs. $22.77 \pm 0.91\left(\times 10^{-3}\right), \mathrm{P}<0.0001$ and $0.191 \pm 0.027$ vs. $0.405 \pm 0.014, \mathrm{P}<0.0001$, respectively) in agreement with previous reports [1-6].

Neither proinsulin/C-peptide ratio nor proinsulin /IRI ratio in patients with Type 2 diabetes was correlated with age or duration of diabetes. As shown in Fig. 1A, fasting proinsulin concentrations in patients with Type 2 diabetes were significantly correlated with BMI $(r=0.353, \mathrm{P}<0.0001)$, whereas neither proinsulin/C-peptide ratio nor proinsulin /IRI ratio was correlated with BMI (Fig. 1B and Fig. 1C). As shown in Fig. 2, both proinsulin/Cpeptide ratio and proinsulin/IRI ratio were significantly positively correlated with FPG $(r=0.236$, $\mathrm{P}=0.0001$ and $\mathrm{r}=0.248, \mathrm{P}=0.0001$, respectively) (Fig. 2A and Fig. 2C) and $\mathrm{HbA}_{1 \mathrm{c}}(\mathrm{r}=0.224$, $\mathrm{P}=0.0003$ and $\mathrm{r}=0.196, \mathrm{P}=0.0023$, respectively) (Fig. 2B and Fig. 2D) in patients with Type 2 diabetes.

To look at the effect of hypoglycemic agents, the fasting proinsulin/C-peptide ratio and the proinsulin/IRI ratio in sulfonylurea-, non-sulfonylurea agent-, combination of sulfonylurea and non-sul-
(A)

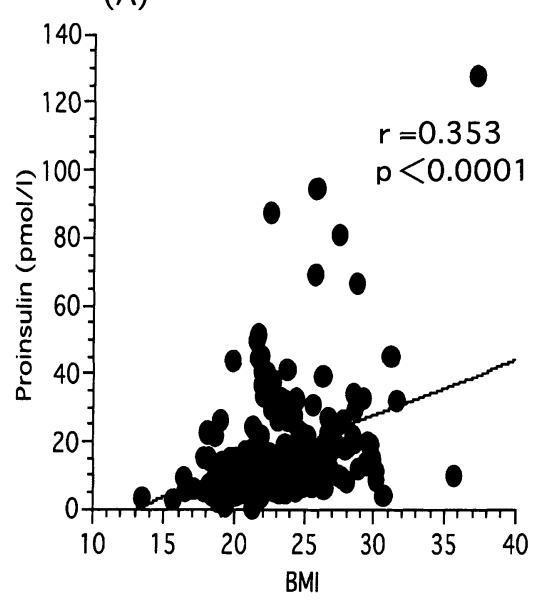

(B)

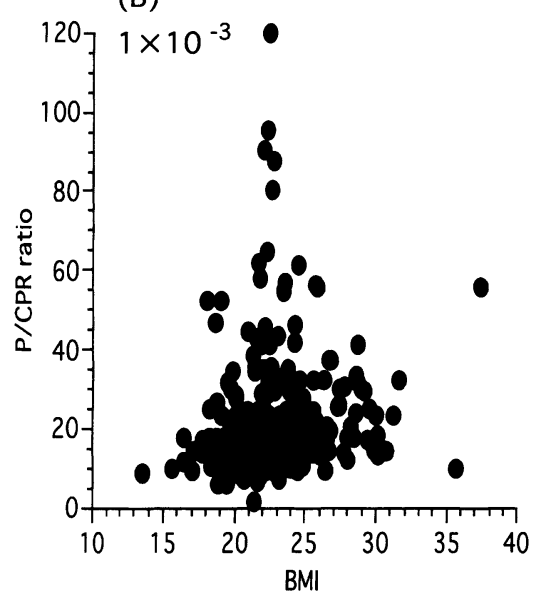

(C)

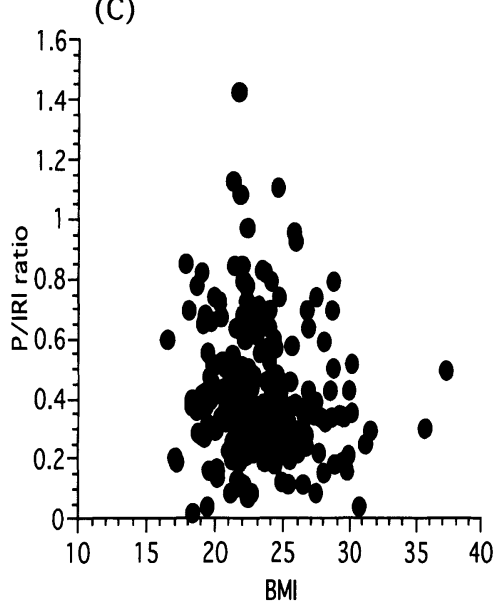

Fig. 1. Correlation between body mass index (BMI) and fasting proinsulin concentration, proinsulin/C-peptide ratio or proinsulin/IRI ratio in patients with Type 2 diabetes. P/CPR ratio: fasting proinsulin concentration to C-peptide concentration ratio $\left(\times 10^{-3}\right), \mathrm{P} / \mathrm{IRI}$ ratio: fasting proinsulin concentration to IRI ratio. 
(A)

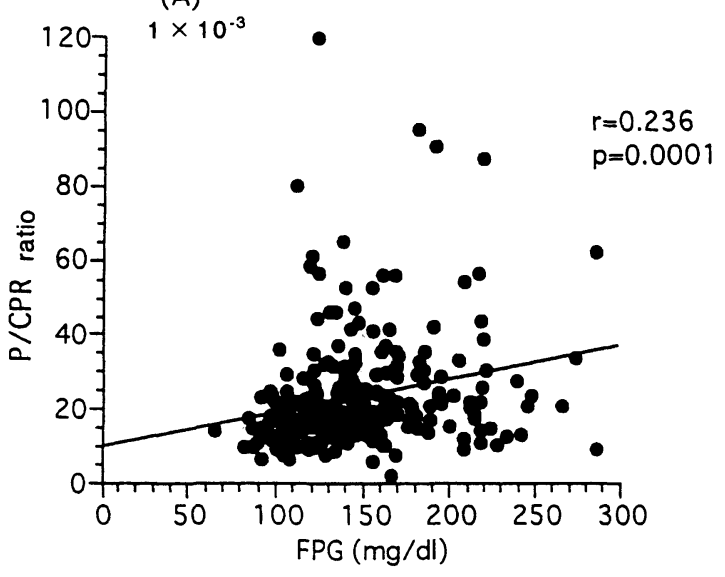

(C)

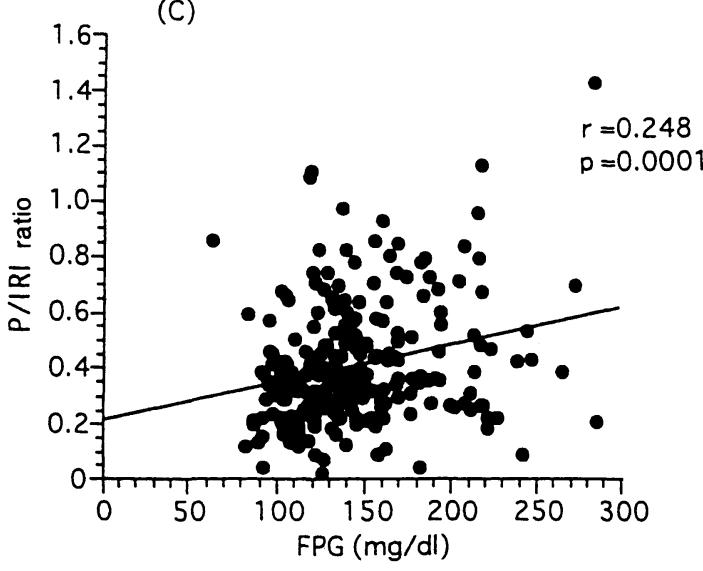

(B)

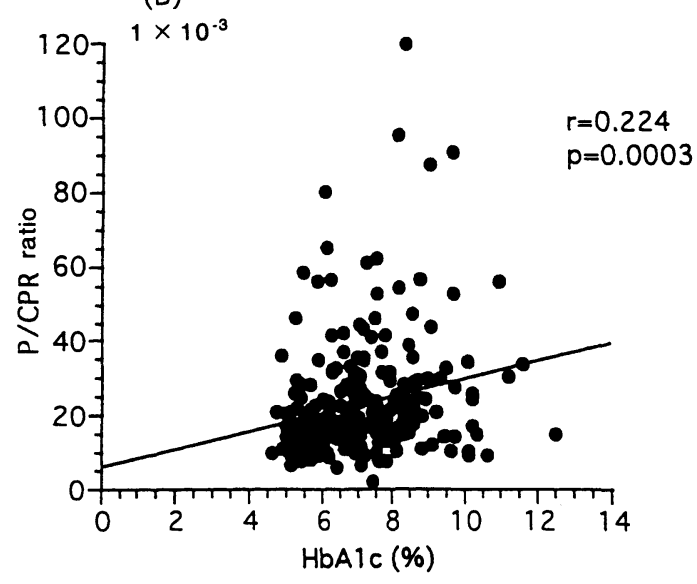

(D)

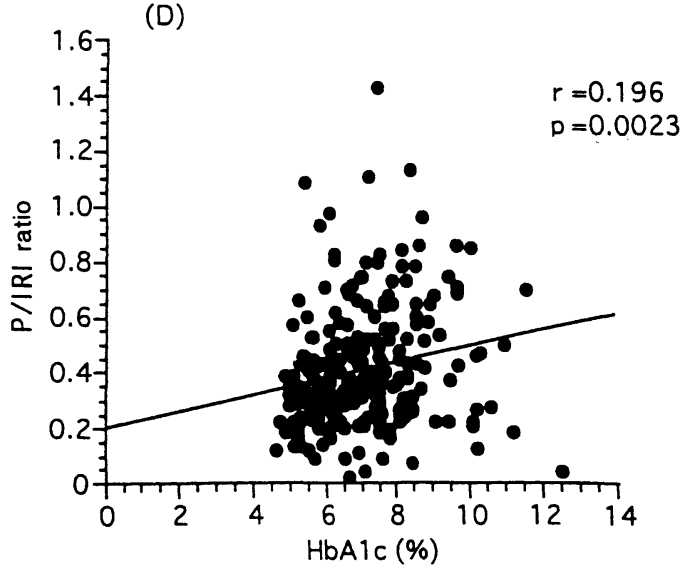

Fig. 2. Correlation between glucose control state and fasting proinsulin/C-peptide ratio or proinsulin/IRI ratio in patients with Type 2 diabetes. P/CPR ratio: fasting proinsulin concentration to C-peptide concentration ratio $\left(\times 10^{-3}\right), \mathrm{P} / \mathrm{IRI}$ ratio: fasting proinsulin concentration to IRI ratio.

fonylurea agent- or insulin-treated subjects were compared with those in diet-treated subjects. Sulfonylurea-treated subjects had a significant elevation in both proinsulin/C-peptide ratio and proinsulin /IRI ratio $(P=0.0054$ and $P=0.0001$, respectively) compared with diet-treated subjects, with a significant elevation in fasting proinsulin concentrations $(P=0.0118)$ (Table 2). Combination of sulfonylurea and non-sulfonylurea-treated subjects also had a significant elevation in both proinsulin/C-peptide ratio and proinsulin/IRI ratio compared with diet-treated subjects $(P=0.0091$ and $P=0.0319$, respectively), with a significant elevation in fasting proinsulin concentrations $(P=0.0174)$ (Table 2$)$. In contrast, insulin-treated subjects had only a significant elevation in proinsulin/C-peptide ratio compared with diet-treated subjects $(P=0.0001)$ (Table
2), without an elevation in fasting proinsulin concentrations. There was no significant difference in proinsulin/C-peptide ratio or proinsulin/IRI ratio between non-sulfonylurea-treated subjects and diettreated subjects.

To confirm what variables were determinants of fasting proinsulin/C-peptide ratio or proinsulin/IRI ratio, multivariate analysis was also performed in the present study. According to the multivariate analysis, sulfonylurea treatment and FPG were significant determinants of both fasting proinsulin/C-peptide ratio $(P=0.006$ and $P=0.030$, respectively) and proinsulin/IRI ratio $(P=0.003$ and $P=0.016$, respectively) in patients with Type 2 diabetes (Table 3). Duration of diabetes was a significant $(\mathrm{P}=0.016)$ determinant of fasting proinsulin/C-peptide ratio (Table 3). 
Table 2. Comparison of fasting proinsulin, C-peptide, IRI, proinsulin/C-peptide ratio and proinsulin/IRI ratio between diet-treated subjects and hypoglycemic agent-treated subjects.

\begin{tabular}{lccccc}
\hline Variables & Diet & SU & SU + Non-SU & Non-SU & Insulin \\
\hline Proinsulin (pmol/l) & $12.9 \pm 1.4$ & $17.3 \pm 1.3^{\S}$ & $20.2 \pm 3.5^{\S}$ & $14.5 \pm 1.7$ & $15.9 \pm 3.4$ \\
C-peptide (nmol/l) & $0.66 \pm 0.04$ & $0.72 \pm 0.03$ & $0.75 \pm 0.07$ & $0.69 \pm 0.05$ & $0.55 \pm 0.08$ \\
IRI (pmol/l) & $51.8 \pm 12.6$ & $40.1 \pm 2.3$ & $53.8 \pm 8.7$ & $43.3 \pm 6.7$ & - \\
Proinsulin/C-peptide ratio $\left(\times 10^{-3}\right)$ & $18.3 \pm 1.1$ & $24.1 \pm 1.5^{\dagger}$ & $25.6 \pm 2.0^{\dagger}$ & $20.6 \pm 2.0$ & $30.8 \pm 7.6^{\|}$ \\
Proinsulin/IRI ratio & $0.34 \pm 0.02$ & $0.47 \pm 0.03^{\|}$ & $0.46 \pm 0.05^{*}$ & $0.39 \pm 0.04$ & - \\
\hline
\end{tabular}

Data are mean \pm SE. Significance of variables was determined by Dunnett's Post-hoc analysis. ${ }^{*} \mathbf{P}<0.05, \& \mathbf{P}<0.02$, ${ }^{\dagger} \mathbf{P}<0.01$, ${ }^{\|} \mathbf{P}<0.001$, vs. diet-treated subjects. Diet; diet-treated subjects. SU; sulfonylurea-treated subjects. Non-SU; non-sulfonylurea hypoglycemic agent (alfa-glucosidase inhibitor, metformin, and troglitazone)-treated subjects. Insulin; insulin-treated subjects.

Table 3. Partial correlation coefficients assessed by multivariate analysis between proinsulin/C-peptide ratio or proinsulin/IRI ratio and different variables in patients with Type 2 diabetes.

\begin{tabular}{lrrrrrr}
\hline & \multicolumn{2}{c}{ Proinsulin/C-peptide ratio } & & \multicolumn{2}{c}{ Proinsulin/IRI rato } \\
\cline { 2 - 3 } \cline { 5 - 6 } Variables & $\mathrm{r}$ & & $\mathrm{P}$ & & $\mathrm{r}$ & $\mathrm{P}$ \\
\hline Age & -0.115 & 0.147 & & -0.001 & 0.994 \\
Duration of diabetes & 0.208 & $0.016^{\S}$ & & 0.155 & 0.074 \\
BMI & 0.040 & 0.617 & & -0.100 & 0.207 \\
FPG & 0.170 & $0.030^{*}$ & & 0.189 & $0.016^{\S}$ \\
HbAlc & 0.051 & & 0.521 & & 0.012 & 0.149 \\
SU treatment & 0.215 & & $0.006^{\dagger}$ & & 0.228 & $0.003^{\dagger}$ \\
Non-SU treatment & 0.031 & & 0.321 & & 0.015 & 0.851 \\
Insulin treatment & -0.077 & & 0.326 & & - & - \\
\hline
\end{tabular}

r; partial correlation coefficient. P; P value. Significance of variables was determined by multivariate analysis. BMI; body mass index. FPG; fasting plasma glucose concentration. SU; sulfonylurea treatment. Non-SU; non-sulfonylurea hypoglycemic agent (alfa-glucosidase inhibitor, metformin, or troglitazone) treatment. ${ }^{*} \mathbf{P}<0.05$, \& $\mathrm{P}<0.02,{ }^{\dagger} \mathrm{P}<0.01$.

In sulfonylurea-treated subjects, both fasting proinsulin/C-peptide ratio and proinsulin/IRI ratio were even more significantly positively correlated with FPG $(r=0.278, P=0.0015$ and $r=0.260, P=$ 0.0049, respectively) (Fig. 3A and Fig. 3B).

\section{Discussion}

The results of our study can be summarized as follows; 1) Both fasting proinsulin/C-peptide ratio and proinsulin/IRI ratio were approximately 2 -fold higher in Japanese patients with Type 2 diabetes than those in healthy nondiabetic subjects, in agreement with previous reports [1-6]. 2) Both fasting proinsulin/C-peptide ratio and proinsulin/IRI ratio in patients with Type 2 diabetes were significantly associated with sulfonylurea treatment and hyperglycemia, as assessed by both univariate and multivariate analysis. The positive correlation between disproportionate hyperproinsulinemia and degree of hyperglycemia in patients with Type 2 diabetes was in accordance with previous reports [3, 7-9]. In contrast, the present finding that disproportionate hyperproinsulinemia was significantly affected by sulfonylurea treatment was at marked variance with 
(A)

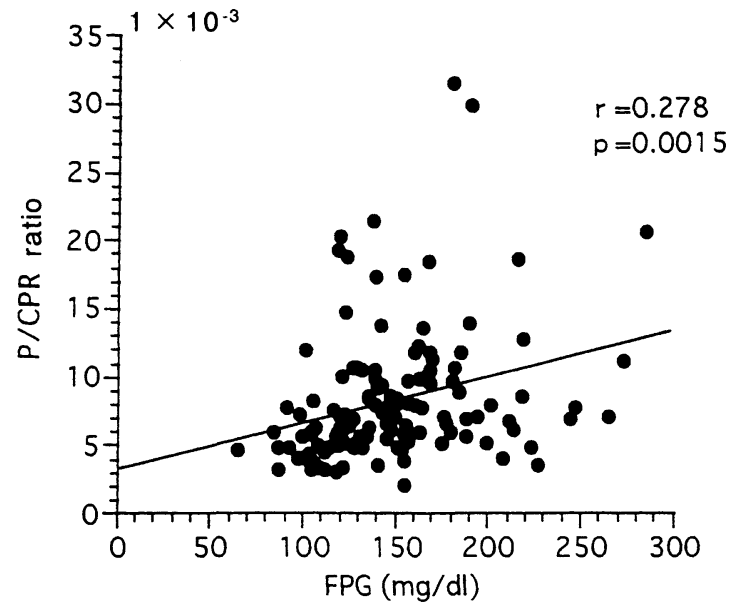

(B)

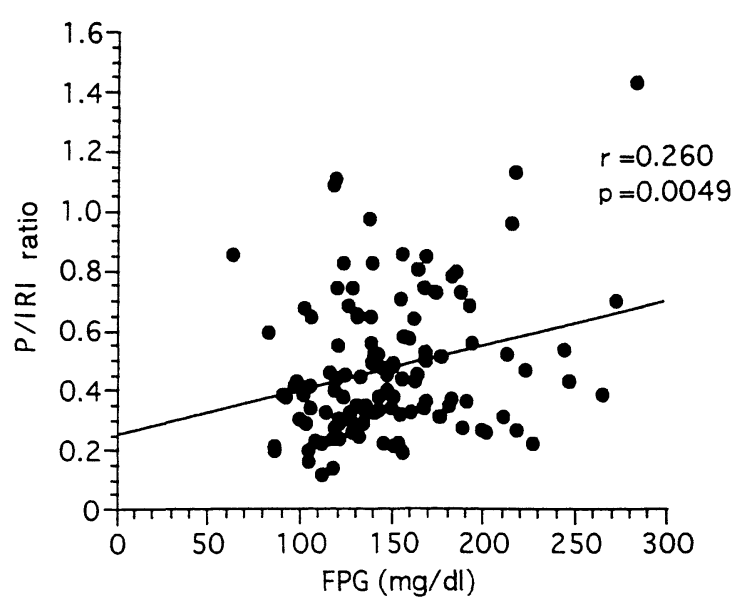

Fig. 3. Correlation between glucose control state and fasting proinsulin/C-peptide ratio or proinsulin/IRI ratio in sulfonylurea-treated patients with Type 2 diabetes. P/CPR ratio: fasting proinsulin concentration to C-peptide concentration ratio $\left(\times 10^{-3}\right), \mathrm{P} / \mathrm{IRI}$ ratio: fasting proinsulin concentration to IRI ratio.

previous experimental studies that showed that sulfonylurea treatment had no effect on disproportionate hyperproinsulinemia or even restored it in patients with Type 2 diabetes [12-15].

Disproportionate hyperproinsulinemia in patients with Type 2 has been well established, but the mechanism remains unclear. This alteration appears to be due to disproportionate hypersecretion of proinsulin rather than increased clearance of insulin, since disproportionate hyperproinsulinemia has also been found after acute stimulation of $\beta$ cells in patients with Type 2 diabetes $[4,18]$. Several explanations for the mechanism of disproportionate proinsulin hypersecretion have been proposed. Disproportionate hyperproinsulinemia could be secondary to external factors acting on the $\beta$ cells such as hyperglycemia, a primary $\beta$-cell defect in proinsulin processing, or combination of both. The present results showed, in accordance with previous reports, the positive correlation between elevation of fasting proinsulin/IRI (or proinsulin/C-peptide) ratio and degree of hyperglycemia. Sustained secretory demand on the $\beta$ cells in response to hyperglycemia may deplete mature granules so that immature proinsulin-rich granules end up being released. Alternatively, chronic hyperglycemia could impair proinsulin processing. The latter seems to be unlikely, since recent experimental study showed that human islets chronically exposed to high glucose concentration for $24 \mathrm{hrs}$ or 8 days did not decrease the proinsulin con- version to insulin, but rather accelerated it [19]. The former has been supported by a variety of evidence. One report showed that $90 \%$ pancreatectomized rats with resultant hyperglycemia induced a fall in insulin content, subsequently resulting in a raised proportion of proinsulin in pancreas extracts [10]. A similar finding was observed in hemipancreatectomy in humans, showing that a disproportionate elevation in fasting proinsulin levels occurred [11]. These findings are supported by the recent report showing that disproportionate hyperproinsulinemia was inversely correlated with maximal acute insulin response (AIR max), which reflects a maximal insulin secretory reserve capacity [20]. Furthermore, the present results showing that sulfonylurea treatment as well as hyperglycemia were associated with a disproportionate hyperproinsulinemia in patients with Type 2 diabetes supported the notion that sustained secretory demand on the $\beta$ cells caused a disproportionate hyperproinsulinemia. In contrast, several reports have shown that the increased $\beta$ cell demand due to insulin resistance fails to result in a disproportionate hyperproinsulinemia. Kahn et al. showed that the induction of experimental insulin resistance with nicotinic acid had no effect on the proinsulin/IRI ratio in normal baboons [21]. Another report also showed that insulin resistance was associated with a low rather than a high proinsulin/IRI ratio in normoglycemic subjects [22]. A possible explanation for these discrepant findings is that the highly exces- 
sive demand on the $\beta$ cells enough to induce a reduction in pancreatic insulin content may be critical for the disproportionate hyperproinsulinemia. Although insulin resistance without hyperglycemia may induce an increased secretory demand on the $\beta$ cells, it is possible that this effect may be too small to cause a reduction in pancreatic insulin content and a subsequent increase in proinsulin secretion.

The present results regarding the effect of sulfonylurea treatment are quite inconsistent with previous reports showing that short-term treatment by sulfonylurea (4 or 8 weeks) did not affect the disproportionate elevation in fasting proinsulin levels [12-14] or restored it in patients with Type 2 diabetes [15]. In these experimental conditions, the increased demand on the $\beta$ cells by sulfonylurea treatment may be negated by a concomitant reduction in hyperglycemia. Chronic treatment with sulfonylurea without a reduction in hyperglycemia may induce the highly excessive demand on the $\beta$ cells and subsequently result in a disproportionate hyperproinsulinemia in patients with Type 2 diabetes. The present results showed that disproportionate hyperproinsulinemia was still positively correlated with the degree of hyperglycemia in sulfonylurea-treated patients.

Several prospective studies have implied that disproportionate hyperproinsulinemia may predict the later development of Type 2 diabetes in subjects with impaired glucose tolerance or normal glucose tolerance [23-25]. Since the present study was cross-sectional, it was unclear whether disproportionate hyperproinsulinemia induced by sulfonylurea treatment or hyperglycemia might be a predictor of a subsequent progress in $\beta$ cell defect. From this point of view, prospective studies should be done to explore whether disproportionate hyperproinsulinemia is a marker of progressive $\beta$ cell defect, so-called $\beta$ cell exhaustion.

In conclusion, both fasting proinsulin/C-peptide ratio and proinsulin/IRI ratio in patients with Type 2 diabetes were significantly associated with sulfonylurea treatment and hyperglycemia assessed by multivariate analysis. Disproportionate hyperproinsulinemia in patients with Type 2 diabetes may reflect an excessive overwork of the $\beta$ cells induced by chronic sulfonylurea treatment and hyperglycemia. Further study is needed to assess the clinical importance of disproportionate hyperproinsulinemia as a marker of progressive beta cell defect.

\section{Acknowledgments}

The authors wish to thank M. Takada (Yuka Medias, Co.) for useful advice regarding statistical analysis.

\section{References}

1. Duckworth WC, Kitabachi AE, Heinemann M (1972) Direct measurement of plasma proinsulin in normal and diabetic subjects. Am J Med 53: 418-427.

2. Gorden P, Hendricks CM, Roth L (1974) Circulating proinsulin-like component in man: increased proportion in hypoinsulinemic states. Diabetologia 10: 469474.

3. Mako ME, Starr JI, Rubenstei AH (1977) Circulating proinsulin in patients with maturity onset diabetes. Am J Med 63: 865-869.

4. Ward WK, LaCava EC, Paquette TL, Beard JC, Wallum BJ, Porte D Jr (1987) Disproportionate elevation of immunoreactive proinsulin in type 2 (noninsulin-dependent) diabetes mellitus and in experimental insulin resistance. Diabetologia 30: 698702 .

5. Deacon CF, Schleser-Mohr S, Ballmann M, Willms B, Conlon JM, Creutzfeldt W (1988) Preferential release of proinsulin relative to insulin in non-insulin-dependent diabetes mellitus. Acta Endocrinol 119: 549-554.

6. Yoshioka N, Kuzuya T, Matsuda A, Taniguchi M, Iwamoto Y (1988) Serum proinsulin levels at fasting and after oral glucose load in patients with type 2 (non-insulin-dependent) diabetes mellitus. Diabetologia 31: 355-360.

7. Saad MF, Kahn SE, Nelson RG, Pettitt DJ, Knowler WC, Schwartz MW, Kowalyk S, Bennett PH, Porte D (1990) Disproportionately elevated proinsulin in Pima Indians with noninsulin-dependent diabetes mellitus. J Clin Endocrinol Metab 70: 1247-1253.

8. Levy JC, Clark PM, Hales CN, Turner RC (1993) Normal proinsulin responses to glucose in mild type II subjects with subnormal insulin response. Diabetes 42: $162-169$.

9. Kahn SE, Leonetti DL, Prigeon RL, Boyko EJ, 
Bergstrom RW, Fujimoto WY (1995) Relationship of proinsulin and insulin with non-insulin dependent diabetes mellitus and coronary heart disease in Japanese-American men: impact of obesity - Clinical Research Center study. J Clin Endocrinol Metab 80: 1399-1406.

10. Leahy JL, Halban PA, Weir GC (1991) Relative hypersecretion of proinsulin in rat model of NIDDM. Diabetes 40: 985-989.

11. Seaquist ER, Kahn SE, Clark PM, Hales N, Porte D Jr, Robertson RP (1996) Hyperproinsulinemia is associated with increased beta cell demand after hemipancreatectomy in humans. J Clin Invest 97: 455460.

12. Davies MJ, Metcalfe J, Day JL, Grenfell A, Hales CN, Gray IP (1994) Effect of sulfonylurea therapy on plasma insulin, intact and $32 / 33$ split proinsulin in subjects with type 2 diabetes mellitus. Diabet Med 11: 293-298.

13. Prigeon RL, Jacobson RK, Porte D, Kahn SE (1996) Effect of sulfonylurea withdrawal on proinsulin levels, B cell function, and glucose disposal in subjects with non-insulin- dependent diabetes mellitus. J Clin Endocrinol Metab 81: 3295-3298.

14. Rachman J, Levy JC, Barrow BA, Manley SE, Turner RC (1997) Relative hyperproinsulinemia of NIDDM persists despite the reduction of hyperglycemia with insulin or sulfonylurea therapy. Diabetes 46 : 1557-1562.

15. Duckworth WC, Solomon SS, Kitabachi AE (1972) Effect of chronic sulfonylurea therapy on plasma insulin and proinsulin levels. J Clin Endocrinol Metab 35: 585-591.

16. Nagi DK, Ali VM, Yudkin JS (1996) Effect of metformin on intact proinsulin and des 31, 32 proinsulin concentrations in subjects with non-insulin-dependent (type 2) diabetes mellitus. Diabet Med 13: 753757.

17. Emura M, Nakanome H, Ito A (1997) Immunoreac- tive proinsulin detected by enzyme-linked immunosorbent assay. Biochem Res 18: 389-393.

18. Kahn ES, Halban PA (1997) Release of incompletely processed proinsulin is the cause of the disproportionate proinsulinemia of NIDDM. Diabetes 46: 1725-1732.

19. Usac EF, Nadal B, Gasa R, Fernandez-Alvarez J, Gomis R (1998) Effect of high glucose concentration on proinsulin biosynthesis and conversion by human islets. Biochem Biophys Res Commun 248: 186-189.

20. Roder ME, Porte D Jr, Schwartz RS, Kahn SE (1997) Disproportionately elevated proinsulin levels reflect the degree of impaired B cell secretory capacity in patients with noninsulin-dependent diabetes mellitus. $J$ Clin Endocrinol Metab 83: 604-608.

21. Kahn SE, Beard JC, Schwartz MW, Ward WK, Lun Ding H, Bergman RN, Taborsky GJ, Porte D Jr (1989) Increased beta-cell secretory capacity as mechanism for islet adaptation to nicotinic acid-induced insulin resistance. Diabetes 38: 562-568.

22. Mykkanen L, Haffner SM, Hales N, Ronnemaa T, Laakso M (1997) The relation of proinsulin, insulin, and proinsulin-to-insulin ratio to insulin sensitivity and acute insulin response in normoglycemic subjects. Diabetes 46: 1990-1995.

23. Kahn SE, Leonetti DL, Prigeon RL, Boyko EJ, Bergstrom RW, Fujimoto WY (1995) Proinsulin as a marker for the development of NIDDM in JapaneseAmerican men. Diabetes 44: 173-179.

24. Mykkanen L, Haffner SM, Kuusisto J, Pyorala K, Hales CN, Laakso M (1995) Serum proinsulin levels are disproportionately increased in elderly prediabetic subjects. Diabetologia 38: 1176-1182.

25. Haffner SM, Gonzalez C, Mykkanen L, Stern M (1997) Total immunoreactive proinsulin, immunoreactive insulin and specific insulin in relation to conversion to NIDDM: the Mexico City Diabetes Study. Diabetologia 40: 830-837. 